\title{
Benefit-incidence analysis of government spending on Ministry of Health outpatient services in Jordan
}

\author{
Y. Halasa, ${ }^{1}$ H. Nassar ${ }^{2}$ and H. Zaky ${ }^{2}$
}

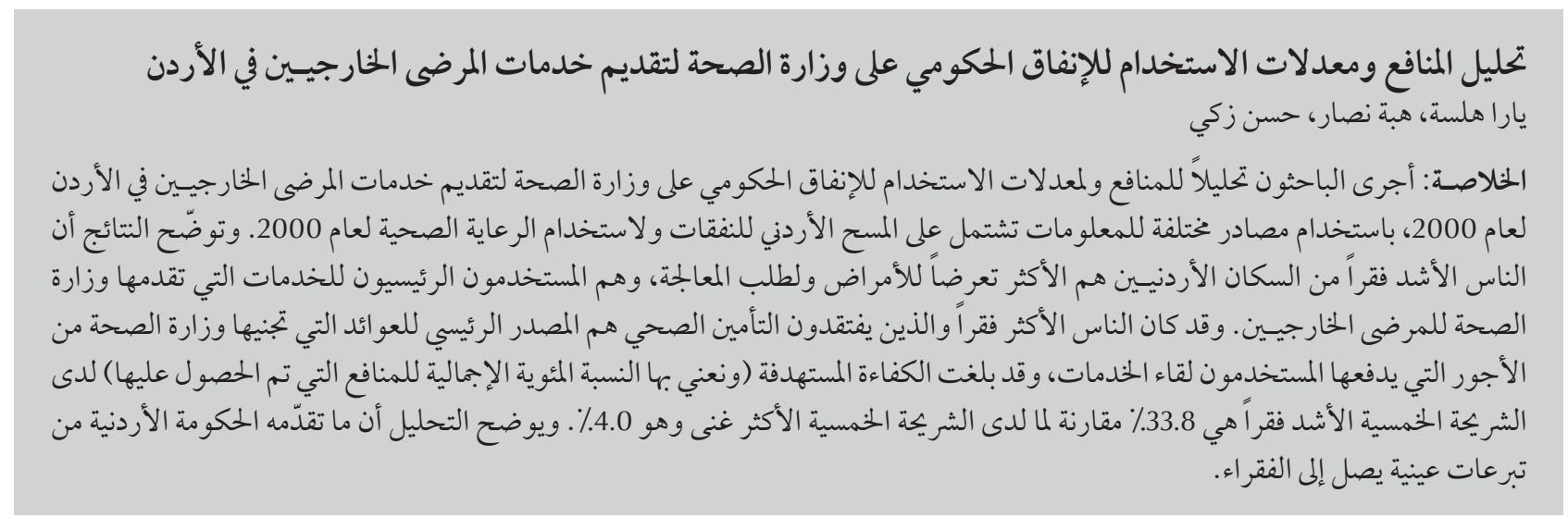

ABSTRACT A benefit-incidence analysis was conducted for the year 2000 using various data sources including the Jordan healthcare utilization and expenditure survey 2000. The results illustrate that the poorest segment of the Jordanian population were the most likely to report sickness and seek treatment and were the main users of the Ministry of Health outpatient services. The poorest uninsured individuals were the main source of revenues generated through user fees. The targeting efficiency (i.e. total percentage of benefits received) for the poorest quintile was $33.8 \%$ compared with $4.0 \%$ in the richest quintile. The analysis demonstrates that the Jordanian government in-kind subsidy is reaching the poor.

Analyse de l'incidence des dépenses publiques pour les consultations externes du ministère de la Santé en Jordanie

RÉSUMÉ Une analyse de l'incidence des avantages a été effectuée pour l'année 2000, à l'aide de différentes sources de données, y compris l'enquête sur l'utilisation des soins de santé et les dépenses afférentes réalisée en Jordanie en 2000. Les résultats montrent que les individus de la couche la plus pauvre de la population jordanienne sont les plus susceptibles de déclarer une maladie et de rechercher des soins, et sont les principaux utilisateurs des consultations externes du ministère de la Santé. Les personnes les plus pauvres, qui n'ont pas d'assurance, représentent la principale source de revenus générés par le paiement direct des usagers. L'efficacité du ciblage (c'est-à-dire le pourcentage total des prestations reçues) pour le quintile le plus pauvre est de 33,8 \%contre 4,0\% pour le quintile le plus riche. L'analyse a démontré que les prestations en nature du gouvernement jordanien parviennent au quintile le plus pauvre.

${ }^{7}$ Schneider Institutes for Health Policy, Brandeis University, Waltham, Massachusetts, United States of America (Correspondence to Y. Halasa: yara@brandeis.edu).

${ }^{2}$ Cairo University and Social Research Center, American University in Cairo, Cairo, Egypt.

Received: 10/09/07; accepted: 12/05/08 


\section{Introduction}

Recent health systems reforms in developing countries have been dominated by neo-liberal concepts, including introduction of user fees, cost recovery, reallocation of resources from curative to preventive care and large reductions in public expenditure. These reforms were implemented on the principle of improving the efficiency of government social interventions $[1,2]$. The results, however, have been devastating in many countries, including those with previously strong health systems, such as in Eastern Europe, where health indicators and health system outcomes have deteriorated [3]. Additionally, these reforms have contributed to health inequities by undermining the capacities of health systems in low- and middle-income countries. Inequity has further increased through the cost burdens imposed by user fees and the international migration of scarce human resources [2].

Jordan, like other countries in transition, faces problems of debt, poverty and unemployment. These challenges, combined with demographic changes, water shortages and limited natural resources, motivated the government of Jordan to launch a social and economic transformation plan, with the objectives ofimproving economic growth, alleviating poverty and improving the quality of public services $[4,5]$. Good health status is recognized as essential for improving the earning potential of the population, particularly the poor $[1,6]$. In 2004, the Jordanian Ministry of Health $(\mathrm{MOH})$ ended the first stage of a long-term health reform that focused on containing growth in health expenditure, assuring efficient utilization of facilities and improving the quality and delivery of health care services [7]. Building on this foundation, a second phase was developed to address issues related to equity, quality, management, pricing policies, cost-effectiveness and the public/private mix in health care [4]. To address "inefficient" pricing policies and to generate resources, $\mathrm{MOH}$ decided in 2004 to re-evaluate its pricing policies for services provided through $\mathrm{MOH}$ facilities at all levels of care. A decision was reached to increase user fees gradually to reach full cost recovery within 5 years.

Benefit-incidence analysis is utilized in this paper to bridge the gap in current knowledge about the efficiency of using government subsidies for outpatient services provided by Jordanian $\mathrm{MOH}$ health care centres, i.e. whether government health care subsidies reach their target group, and the possible role these subsidies play in enhancing equity of access to basic health care services in Jordan.

\section{Methods}

A benefit-incidence analysis was used, with the year 2000 as the reference year, to measure the extent to which different groups within the Jordanian population capture the public subsidy provided through public provision of health care services $[1,8,9]$. This paper focuses on public subsidies to outpatient services provided at $\mathrm{MOH}$ health centres (primary and comprehensive).

\section{Health system in Jordan}

Jordan's health sector is an amalgam of several separate private and public subsystems. The MOH finances and delivers care for civil servants and their dependants, andtopatientswhocannotorchoose not to use other providers. The ministry operates hospitals as well as health units, primary health care centres and comprehensive health care centres (the health units and centres will be the focus of this paper and will be referred to as HCC). The Royal Medical Services finances and delivers care to military personnel and their dependents. Other smaller public programmes include several universitybased programmes, such as the University of Jordan and the King Abdullah the First teaching hospital. In addition, several nongovernmental organizations
(NGOs) and donor-owned and -operated facilities exist, the largest being the United Nations Relief and Works Agency (UNRWA), which provides care mostly to Palestinian refugees. There is a sizeable private sector including doctor's offices, clinics and hospitals [10].

A survey conducted in 2000 found that $60 \%$ of the Jordanian population are insured and that $6 \%$ of those insured have multiple insurances, whereas $40 \%$ had no insurance cover [11].

\section{Sources of data}

Our main source of information on utilization of health services and out-ofpocket (OOP) expenditure by wealth quintiles was the Jordan healthcare utilization and expenditure survey 2000, a nationally representative survey of 8306 households and 49000 individuals [11]. Individuals were asked whether, conditional on being ill, they had used a health care provider in the past 2 weeks. The data showed that 1031 individuals had made an outpatient visit in the 2 weeks preceding the survey and all of them were included in the analysis.

Two sources of data were used to estimate service unit cost of public subsidy for the benefit-incidence analysis. First, the Jordanian national health accounts 2000-2001 provides estimates at the national level of public expenditure on $\mathrm{MOH}$ HCC $[10]$. For the purpose of this analysis only resources from the Ministry of Finance (MOF) were used as real expenditure in $\mathrm{MOH} \mathrm{HCC}$, since funds from other sources (household and Royal Medical Services) are not kept at the facility level. The second source was Rationalizing staffing patterns and cost analysis of primary health services in Jordan 1999, a facility-based study funded by the United States Agency for International Development [12].

Other documents were also used, such as the $\mathrm{MOH}$ fee lists and drug co-payments list as well as revenue documents from the national health insurance administration, to ensure data consistency and reliability. This 
approach of combining data from the Jordanian national health accounts [9] with other sources from nationally representative surveys extends the earlier tradition of benefit-incidence studies to allow a direct comparison of the distribution of public and private expenditures [13].

For the purpose of this study, government spending on $\mathrm{HCC}$ was the product of the average unit cost of $\mathrm{MOH}$ outpatient centres obtained from the staffing patterns and cost analysis report [12] (adjusted to the inflation rate) and the utilization data obtained from the health care utilization and expenditure survey $[11]$. The results were compared with corresponding data from the Jordanian national health accounts [9] to ensure consistency and reliability.

\section{Definitions}

Public subsidies for health services were valued as an indirect transfer from the government to households, on condition that households use government services [1]. The unit transfer was calculated as the actual cost to the government of providing the services. These were not valued at the market price of such services but as the net cost to the government, excluding any income the public facilities received from user fees or the insurance premiums paid by the insured in the civil insurance programme.

Outpatient services were defined as all services that involved individuals' contact with health care providers and did not involve an overnight stay. In the current analysis, all outpatient services provided at $\mathrm{MOH}$ hospitals were excluded from the benefit-incidence analysis due to the limited data available on costing and utilization.

Private health expenditure was related to household OOP spending on health, and was defined as all expenditure by households for direct purchasing of medical services or supplies. This definition excluded household expenditure on travel costs and any indirect costs associated with seeking care.

An asset-based wealth index classified the population by economic level based on household assets, amenities and services. This index was utilized as a proxy for household economic status. Five quintiles were developed using principal component analysis, as recommended by the World Bank and Macro International [1]. The 1st wealth quintile donates the poorest quintile; the 2 nd the poor; the 3 rd donates the middle quintile; the 4th stands for the rich quintile and the 5 th for the richest quintile. We assumed that an individual within a household had the same wealth quintile as the rest of the household regardless of his/her income, employment status or age.

Targeting efficiency measured the accumulated percentages of benefits received by each wealth quintile.

\section{Implicit assumptions}

Total government spending was taken as the benefit a household or individual received as an in-kind transfer. The value of the service provided was treated similarly to a monetary transfer. During the analysis the average unit cost for $\mathrm{MOH}$ HCC was used as a proxy for unit costs across various levels of $\mathrm{MOH} \mathrm{HCC}$, assuming no differences in the intensity of resources used per treatment per episode across population subgroups $[1,12]$.

\section{Results}

\section{Episodes of illness and health care seeking}

The results showed that the poorest quintile in Jordan were more likely to report illness compared to other quintiles (Table 1). An illness was reported by $5.0 \%$ of the poorest quintile and $4.4 \%$ of the poor, compared with $3.4 \%$ of the rich and $2.9 \%$ of the richest. They were as likely to seek care as other groups except the middle quintile; $64.0 \%$ of the poorest and $59.1 \%$ of the poor who reported sickness sought treatment compared with $70.3 \%$ in the middle quintile and $62.1 \%$ in the richest quintile.

\section{Distribution of health care utilization}

The total utilization pattern in Table 2 illustrates that $54.1 \%$ of all outpatient visits in the year 2000 took place at $\mathrm{MOH}$ facilities (45.7\% at MOH HCC and $8.4 \%$ at hospital outpatient clinics), followed by private providers at $36.1 \%$. The MOH HCC were key providers of outpatient services across all quintiles, with the exception of the rich quintile, where the utilization rate of $\mathrm{MOH}$ HCC and private providers were similar at $41.9 \%$ and $41.8 \%$ respectively. Of visits to $\mathrm{MOH} \mathrm{HCC,} 59.1 \%$ were from patients in the poorest quintile, $52.6 \%$ from the poor, $47.8 \%$ from the middle, $41.9 \%$ from the rich and $13.5 \%$ from the richest.

\begin{tabular}{|c|c|c|c|c|c|c|}
\hline \multirow[t]{3}{*}{ Health experience } & \multicolumn{6}{|c|}{ Wealth index } \\
\hline & Poorest & Poor & Middle & Rich & Richest & All \\
\hline & $\%$ & $\%$ & $\%$ & $\%$ & $\%$ & $\%$ \\
\hline Reporting any illness ${ }^{\mathrm{a}}$ & 5.0 & 4.4 & 3.7 & 3.4 & 2.9 & 3.9 \\
\hline Seeking medical care ${ }^{b}$ & 64.0 & 59.1 & 70.3 & 61.8 & 62.1 & 63.4 \\
\hline
\end{tabular}

a Percentage of individuals reporting any illness within 2 weeks preceding survey; ${ }^{b}$ Percentage of individuals seeking care among those who reported illness. Source: Jordan healthcare utilization and expenditure survey, 2000 [11]. 


\begin{tabular}{|c|c|c|c|c|c|c|}
\hline \multirow{3}{*}{ Type of provider } & \multicolumn{6}{|c|}{ Wealth index } \\
\hline & Poorest & Poor & Middle & Rich & Richest & All \\
\hline & $\%$ & $\%$ & $\%$ & $\%$ & $\%$ & $\%$ \\
\hline $\mathrm{MOH}$ health centre & 59.1 & 52.6 & 47.8 & 41.9 & 13.5 & 45.7 \\
\hline MOH hospital & 8.4 & 8.3 & 11.2 & 7.8 & 5.0 & 8.4 \\
\hline Royal Medical Services & 5.7 & 9.0 & 3.7 & 6.6 & 7.5 & 6.4 \\
\hline NGO & 1.8 & 0.7 & 0.2 & 0.3 & 0.8 & 0.8 \\
\hline UNRWA & 3.4 & 4.7 & 2.1 & 1.6 & 0.3 & 2.7 \\
\hline Private & 21.5 & 24.7 & 35.0 & 41.8 & 72.9 & 36.1 \\
\hline
\end{tabular}

Source: Jordan healthcare utilization and expenditure survey 2000 [11].

$\mathrm{MOH}=$ Ministry of Health; $\mathrm{NGO}=$ nongovernmental organization; UNRWA = United Nations Relief and Works Agency

\section{Distribution of $\mathrm{MOH} \mathrm{HCC}$ utilization}

Of those utilizing $\mathrm{MOH}$ HCC, 33.9\% were from the poorest quintile compared with $24.4 \%$ of the poor, $22.2 \%$ the middle, $15.5 \%$ the rich and $4.0 \%$ the richest quintiles. Figure 1 shows that utilization of $\mathrm{MOH}$ centres decreased with increasing wealth, as $46.8 \%$ of the uninsured individuals utilizing $\mathrm{MOH}$ $\mathrm{HCC}$ were in the poorest quintile compared with $15.6 \%$ in the middle quintile and $3.3 \%$ in the richest quintile.

\section{Distribution of MOH HCC out-of-pocket expenditure}

The result of the financial incidence analysis, illustrated in Table 3 , shows that the poorest quintile, especially the poorest uninsured, was the major contributor of OOP expenditure, accounting for $30.8 \%$ of all OOP expenditure. For uninsured individuals the percentage contributed from OOP expenses decreased as wealth increased. The analysis illustrates that $62.0 \%$ OOP expenditure came from the uninsured. The contributions

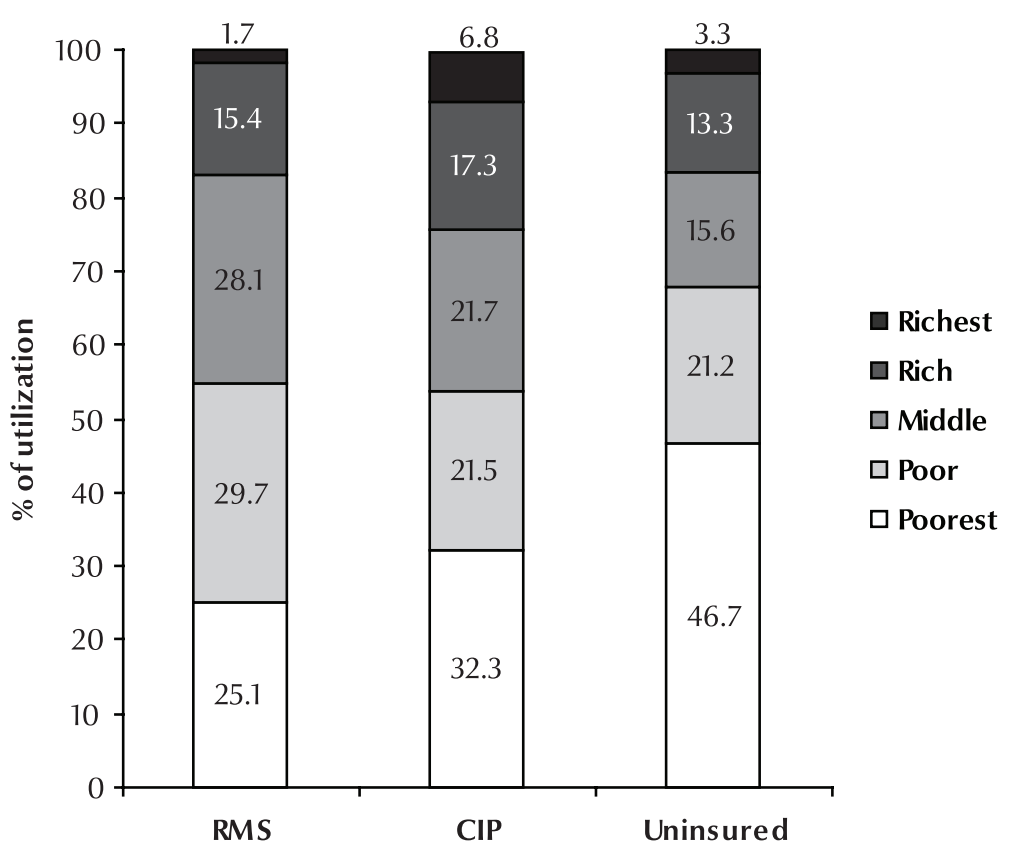

Figure 1 Utilization of Ministry of Health health care centres by individual's type of insurance coverage and wealth index (RMS = Royal Medical Services, CIP = civil insurance programme) from individuals in the civil insurance programme and Royal Medical Services were $21.4 \%$ and $16.7 \%$ respectively and, again, OOP contributions decreased as wealth increased.

\section{Distribution of government subsidy of MOH HCC}

Table 4 illustrates that the average in-kind transfer (net government spending) for all quintiles was $80.2 \%$. Disaggregating the in-kind transfer according to wealth quintiles showed that a lower subsidy went to the poorest quintile (75.6\%) compared with the other quintiles. Additionally, the proportion of OOP paid by the poorest was higher (24.4\%) compared with the middle quintile (16.8\%) and the richest (19.6\%).

\section{Benefit-incidence analysis}

Table 5 shows the benefit-incidence analysis of government spending on $\mathrm{MOH}$ HCC according to individual's wealth quintile and type of insurance. When analysed by quintiles the targeting efficiency (i.e. total percentage of benefits received) demonstrates that individuals in the richest quintile received the lowest subsidy ( $4.0 \%$ of the total benefits), while the poorest quintile received the highest subsidy $(33.8 \%$ of the total benefits). When analysed by type of insurance coverage, the results suggest that individuals with the civil insurance programme and Royal Medical Services insurance were the most likely 


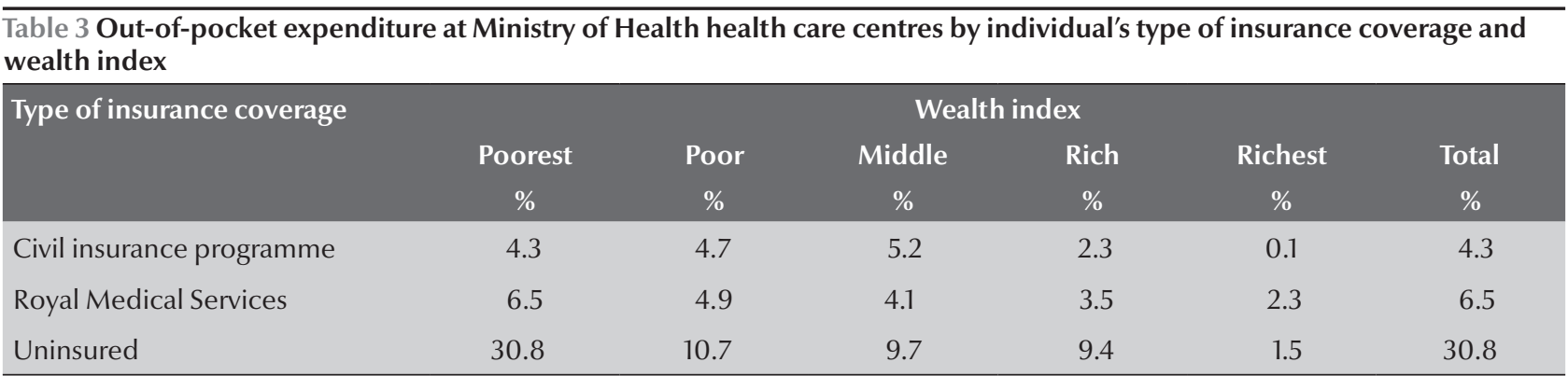

to benefit from the government in-kind subsidy for health (receiving 35.8\% and $35.2 \%$ of benefits respectively), followed by the uninsured (receiving 28.4\%).

Disaggregating the results according to insurance status illustrates that targeting efficiency varied between and within quintiles. For example, in the poor and middle quintiles those with Royal Medical Services insurance benefited most from in-kind transfers for health, followed by individuals in the civil insurance programme and the uninsured respectively. The sub-group of individuals in the poorest quintile who were uninsured received the highest subsidy (13.3\%), followed by those in the poorest quintile who were using the civil insurance programme (11.6\%).

\section{Discussion}

The results suggest that, in contrast to what has been documented in other countries, the poorest and poor quintiles in Jordan, who are presumably sicker and in greater need of health services, are able to recognize illness and seek health care regardless of their economic, employment or insurance status [2,8-10,13-16]. This emphasizes the MOH's role as a safety net for the Jordanian poor, especially the poorest quintile, since $67 \%$ of the poorest quintile chose and utilized $\mathrm{MOH}$ facilities as the first provider for health care $(59 \% \mathrm{MOH}$ HCC and $8 \% \mathrm{MOH}$ hospital-based outpatient clinics), while only $22 \%$ went to private providers. Additionally, it suggests that the government subsidy to health care made it financially accessible to all by reducing the financial burden shouldered by the poor.

As expected, the poor were more likely than the rich to obtain health care from public facilities, suggesting that public spending on health may matter more to the poor. This result is supported by several studies that suggest that public spending on health care reduces poor-rich differences in access to health care [13-17].

\section{Table 4 Government subsidy of Ministry of Health health care centres by individual's wealth index}

\begin{tabular}{|c|c|c|c|c|c|c|}
\hline \multirow[t]{3}{*}{ Payer } & \multicolumn{6}{|c|}{ Wealth index } \\
\hline & Poorest & Poor & Middle & Rich & Richest & All \\
\hline & $\%$ & $\%$ & $\%$ & $\%$ & $\%$ & $\%$ \\
\hline Government ${ }^{\mathrm{a}}$ & 75.6 & 83.5 & 83.2 & 80.7 & 80.4 & 80.2 \\
\hline Household ${ }^{b}$ & 24.4 & 16.5 & 16.8 & 19.3 & 19.6 & 19.8 \\
\hline
\end{tabular}

${ }^{a}$ Based on net government expenditure; ${ }^{b}$ Based on out-of-pocket payment.

Sources: Jordan healthcare utilization and expenditure survey 2000 [11]; Rationalizing staffing patterns and cost analysis of primary health services in Jordan, 1999 [12].

Table 5 Benefit-incidence analysis of government spending at Ministry of Health health care centres, showing targeting efficiency by individual's type of insurance coverage and wealth index

\begin{tabular}{|c|c|c|c|c|c|c|}
\hline \multirow[t]{3}{*}{ Type of insurance coverage } & \multicolumn{6}{|c|}{ Wealth index } \\
\hline & Poorest & Poor & Middle & Rich & Richest & Total \\
\hline & $\%$ & $\%$ & $\%$ & $\%$ & $\%$ & $\%$ \\
\hline Civil insurance programme & 11.6 & 7.8 & 7.8 & 6.2 & 2.4 & 35.8 \\
\hline Royal Medical Services & 8.8 & 10.5 & 9.9 & 5.4 & 0.6 & 35.2 \\
\hline Private insurance & 0.0 & 0.0 & 0.3 & 0.1 & 0.0 & 0.4 \\
\hline Uninsured & 13.3 & 6.0 & 4.4 & 3.8 & 0.9 & 28.4 \\
\hline Total (targeting efficiency) & 33.8 & 24.3 & 22.4 & 15.5 & 4.0 & 100.0 \\
\hline
\end{tabular}


Our results show that the $\mathrm{MOH}$ HCC provided services to all Jordanians regardless of their insurance status [11]. MOH facilities (HCC and hospital-based outpatient clinics) were the most utilized of the outpatient health care providers, at $54 \%$, followed by the private sector, at $36 \%$. Furthermore, $\mathrm{MOH}$ HCC were the main source of outpatient health care services for $46 \%$ of those seeking treatment, especially the poorest uninsured.

Moreover, the proportion of public expenditure on health derived from the government was on average $80 \%$, whilst theproportion derived from households (i.e. OOP expense) was on average $20 \%$, ranging from $24 \%$ in the poorest quintile to $17 \%$ in the poor quintile and $20 \%$ in the richest quintile. The variations in private $\mathrm{OOP}$ contributions across different wealth quintiles - a conclusion supported by Jordan Public Health Expenditure Review-highlights the regressive pattern in private spending on health [17], indicating the need for a better structure of government financing for health, such as scaling prices to reflect ability to pay (price discrimination), targeting programmes utilized by the poor and geographic targeting especially in rural areas with limited health providers.

It is essential to conduct an in-depth study of the levels of OOP expenditure at $\mathrm{MOH}$ facilities to predict the possible impact of any increase in user fees on individuals' care-seeking behaviour. The international literature illustrates that increase in user fees will cause a fall in utilization levels, indicating that health care demand is price elastic. This could be the case in Jordan if the government increased user fees at MOH HCC, since our results show that the poorest uninsured were the main source of revenues for $\mathrm{MOH} \mathrm{HCC}$ and that $\mathrm{MOH}$ HCC were the main source of health care for this group. Additionally, the results of the RAND health insurance experiment, conducted in the USA in the late 1970s, found that "individual's medical care utilization decisions were influenced by prices" and that "price elasticity increases as the coinsurance rate increases". Moreover, demand for acute care and inpatient services were found to be less sensitive to price than chronic care and outpatient care $[18,19]$.

Another area to be considered is the effect of such increases on the private sector. International research examining the effect of increasing public health care fees illustrated that an increase in public fees was more likely to reduce utilization; some patients might switch to other providers, while others would use self-treatment $[20,21]$. Additionally, the increase in demand on private sector services resulting from higher fees in the public sector may result in higher fees in the private sector, as illustrated by the Indonesian experience, and therefore limit the ability of the poor to access health care services when needed [22].

Our results demonstrate that a greater proportion of benefits to those utilizing the MOH HCC was enjoyed by the poorest quintile. The targeting efficiency illustrated that $34 \%$ of resources allocated to health were received by the poorest quintile, $24 \%$ by the poor, $22 \%$ by the third quintile, $16 \%$ by the rich and $4 \%$ by the richest quintile. This strongly suggests that public expenditure for MOH HCC is targeting the poor and other disadvantaged groups effectively.

International experience demonstrates that there are real returns from public subsidies in terms of health outcomes. This can be seen in Jordan, where health indicators are considered among the 10 best in the Middle East/ North Africa region. Therefore, any attempt to lower subsidies by increasing user fees may have negative health consequences, bearing in mind that $\mathrm{MOH}$ HCC are the main health care services for the poorest uninsured quintile in the northern and southern regions of the country [authors' analysis, data not included]. Additionally, international experience demonstrates the elasticity of outpatient visits. If the $\mathrm{MOH}$ chooses to increase fees then "unless the freed subsidies are allocated to more efficacious programmes, health outcomes may deteriorate" [23]. Furthermore, if the suggested increase in user fees is used to generate revenues to improve the quality and access to curative care (as suggested by the $\mathrm{MOH}$ ), and if the wealthy are willing to pay the full cost of service improvement, but the poor are not, then this policy could lead to reallocation of public subsidies from the poor to the wealthy. Thus, any increase in user fees would become a financial barrier to the poor and reduce their access to care [22].

A remedy for lack of collaboration between the $\mathrm{MOH}$ and the private sector needs to be debated by policy-makers, especially in rural areas where the $\mathrm{MOH}$ is the main provider of health. There is a window of opportunity to build public-private partnerships by enabling the private sector to contract with the $\mathrm{MOH}$ to provide services to their employees, especially in rural areas. This could be a realistic option to increase $\mathrm{MOH}$ revenues, and reduce unit costs especially for village health units.

Finally, this paper calls for extreme caution in adopting some of the health care reform packages implemented in other countries, and indicates the urgent need to draw lessons from other countries' experiences during the design and implementation phases of health sector reform in Jordan.

\section{Study limitations}

The analysis did not take into consideration the "intensity" of services at different facilities, and thus underestimated the administrative costs, which might result in a biased analysis and hide the inefficiency of the system.

Some concerns have been raised recently regarding the use of principle component analysis in measuring the 
wealth index as recommended by the World Bank. These concerns are related to the relative position of households in the national wealth hierarchy, which varies to a great extent based on the asset index used and time period studied. There is a chance that the way in which economic status is defined might have influenced the magnitude of poor-rich differences in health and health-related outcomes $[24,25]$. Our data used a question about the first contact with health providers in case of illness and seeking care; as a result the study did not capture the utilization volume. Given the limitation of the data available and the implicit assumptions behind the benefit-incidence analysis, the results should therefore be considered with care.

\section{Acknowledgements}

The authors thank the Social Research Center at the American University in Cairo for making the analysis possible through the research fellowship provided to the first author. The views expressed in this paper are solely those of the authors and any errors or omissions are entirely theirs.

\section{References}

1. Demery L. Benefit incidence: a practitioner's guide. Washington DC, World Bank, 2000.

2. Gilson L et al. Challenging inequity through health systems. WHO Commission on the Social Determinants of Health. Geneva, World Health Organization, 2007.

3. Murthi M. Political economy of health in transition economy: case of Albania. Paper presented at the IUSSP international seminar on Health inequity: current knowledge and new measurement approaches, Cairo, Egypt, 16-18 February, 2008.

4. SETP background. Social and Economic Transformation Program (SETP). Ministry of Planning. Jordan [website] (http://www. mop.gov.jo/pages.php?menu_id=70, accessed 29 October 2009).

5. Jordan development policy review: a reforming state in a volatile region. Washington DC, World Bank, 2002 (Report No. 24425JO).

6. Macroeconomics and health: investing in health for economic development. Report of the Commission on Macroeconomics and Health. Geneva, World Health Organization, 2001.

7. Hashemite Kingdom of Jordan: health sector study. Washington DC, World Bank, 1997.

8. Pearson M. Benefit incidence analysis: how can it contribute to our understanding of health systems performance? London, Department for International Development Health Systems Resource Centre, 2002.

9. Mahal A et al. The poor and health service use in India. Washington DC, Human Development Network, World Bank, 2001 (Health, Nutrition and Population Discussion Paper).

10. Al-Halawani F et al. Jordan national health accounts, 2000 and 2001. Partners for Health Reformplus working paper no. 014. Bethesda, Maryland, Abt Associates, 2006.

11. Nandakumar AK et al. Jordan healthcare utilization and expenditure survey 2000. Cambridge, Massachusetts, Abt Associates, 2002.

12. Mawajdeh $\mathrm{S}$ et al. Rationalizing staffing patterns and cost analysis of primary health services in Jordan, 1999. Bethesda, Maryland, Abt Associates, 2001.

13. Rannan-Eliya R, Blanco-Vidal C, Nandakumar AK. The distribution of health care resources in Egypt: implication of equity. Boston, Massachusetts, Harvard School of Public Health, 1999.
14. Filmer D. Fever and its treatment among the more and less poor in sub-Saharan Africa. Washington DC, World Bank, 2001.

15. Begum $T$ et al. Equity in financing and delivery of health services in Bangladesh, Nepal and Sir Lanka: Results of the tri-country study. New Delhi, World Health Organization Regional Office for South-East Asia, 2001.

16. Gupta S, Verhoeven M, Tiongson E. Public spending on health care and the poor. International Monetary Fund working paper. Washington DC, International Monetary Fund, 2001 (WP/01/127).

17. Jordan: public expenditure review. Washington DC, World Bank, 2004.

18. Manning $\mathrm{W}$ et al. Health insurance and the demand for medical care. American economic review, 1987, 77(3):251-77.

19. Newhouse J. Free for all. Cambridge, Massachusetts, Harvard University Press, 1995.

20. Gertler P, Molyneaux J. Experimental evidence on the effect of raising user fees for publicly delivered health care services: utilization, health outcomes and private provider response. Santa Monica, California, RAND Corporation, 1997.

21. Bennet $\mathrm{S}$. The impact of the increase in userfees. Lesotho epidemiological bulletin 4. Maseru, Lesotho, Ministry of Health Disease Control and Environmental Health Division, 1989.

22. Gilson L. Government health care charges: is equity being abandoned? London, London School of Hygiene and Tropical Medicine, 1988 (EPC publication no. 15).

23. Gertler P, Hammer J. Strategies for pricing publicly provided health services. Policy research working paper no. 1762. Washington DC, World Bank, 1997.

24. Houweling TAJ, Kunst AE, Mackenbach JP. Measuring health inequality among children in developing countries: does the choice of the indicator of economic status matter? International journal for equity in health, 2003, 2:8.

25. Houweling TA et al. Mortality inequalities in times of economic growth: time trends in socioeconomic and regional inequalities in under 5 mortality in Indonesia, 1982-1997. Journal of epidemiology and community health, 2006, 60(1):62-8. 